\title{
Impact of Pilgrimage (Hajj) on the Urban Growth of the Mecca
}

\author{
Ibrahim Elsayed Ascoura \\ Assistant Professor, University of Umm Al-Qura, KSA \\ Department of Geography, Faculty of Arts, Helwan University (Cairo), Egypt. \\ Graduated from the University of Paris 4 (Paris-Sorbonne) \\ E-mail ascoura@hotmail.com; ieascoura@uqu.edu.sa
}

Doi:10.5901/jesr.2013.v3n2p255

\begin{abstract}
The holy city of Makkah is located in the southwest of Saudi Arabia, and it is considered the spiritual capital of one and half billion Muslims worldwide and being visited by millions of pilgrims every year. However, the urban extent of Makah is constrained by the surrounding mountain ranges, but the developments of modern transport means (i.e. roads and ports) has resulted in the increase of pilgrims visiting Makah around the year. Concurrently, the landuse of Makah has drastically changed to cope with the increasing services required for pilgrims. Therefore, the town center of Makah, particularly around the Holy Mosque and the sacred sites of pilgrimage was redeveloped into sets of hotels and stores, which can be considered as the tourism zone in Makah. Moreover, the residential areas has expanded outside the current tourism zone, thus the urban development is being affected by the pilgrims activities. Therefore, this paper investigated the interaction between the evolution of pilgrims numbers, the urban growth and problems arising during the pilgrimage season.
\end{abstract}

Keywords: Saudi Arabia - Geography - pilgrimage - Mecca - Arabic City - urban

\section{Introduction}

The city of Mecca is part of the western region of the Kingdom of Saudi Arabia (Figure 1); it is one of the oldest cities in the world. "Mecca, this "blessed city" located in the foot slopes of the Sarawat hills nearly at 700 meters above sea level, however, as the most venerated holy place of Islam" ${ }^{1}$. The first nuclei of Mecca was laid down by the Prophet Ibrahim some 3700 years ago. The Kabaa (House of God) is considered the heart of the city. Urbanization has crystallized around the Holy Mosque embracing the Kabaa. The built extension was very low. With the discovery of the well of Zamzam², the function of services has become the first characteristic function of the city, where the use of passages adapted convoys for the drinking water supply is necessary. And so it formed the first transport lines that have put the city on the map of urbanism since then. But the importance of the city has not appeared that in the Islamic era, where it was imposed on all Muslims throughout in the whole of the Earth to visit the city to perform the pilgrimage, to every person who has the capacity. The flow of people has started visiting the city each year, and some of them settled permanently in the city leading to a continuous urban sprawl.

The rituals of the pilgrimage are mainly concentrated in four holy places, including ${ }^{3}$, Holy Mosque, Mina, Muzdalifah and Arafat (Figure 2), which are distributed in different regions of the city and its neighborhood. During Hajj, the pilgrims must stay in Mina during the period of execution of the rituals of the pilgrimage (from 8 to 13 of Zo-Al-Hijja ${ }^{4}$ ), however, most of the pilgrims arrive Mecca long before the commence of Hajj and also

1 Le Royaume de l'Arabie Saoudite, 1979, Stacey International, London, p.52

2 The Zamzam well was drilled by the wife of the Prophet Ibrahim Hajar, Prior to the building of Alkabaa, The Basis of the Holy Mosque.

3 The Holy sites are the places that pilgrims will perform the rites of the pilgrimage. These sites consist of four areas in Mecca, the Holy Mosque, Mina, Muzdalifah and Arafat. The last three are empty areas of residential buildings and are equipped with facilities to serve the pilgrims, such as tents for the accommodation of pilgrims, toilets, health centers and security offices.

4 The last month of lunar calendar. 
stay for some time after the fulfillment of Hajj. Therefore, the numerous hotels which are spreading on different areas of the city (especially the nearest holy places) are being over occupied. There are several spiritual reasons and logistic issues behind the long period of pilgrimage staying in Mecca, including but not limited to the organization of the return trip or the visiting to the city of the Prophet of islam (Medina) and shopping. On the other hand, Mecca suffers from population growth, increasing rates of immigration and also from the increasing numbers of foreign labor required for the city. Indeed, all these factors are affecting the urban and facilities available to Mecca.

The Holy City of Mecca annually accommodates more than three million pilgrims ${ }^{5}$ coming from all over the world and also from the different regions within Kingdom of Saudi Arabia, as a result disrupts the urban system and affects the urban dynamics of the city. The pilgrims have led to the development of tourism business, particularly in the heart of the city (near the Holy Mosque). The market value of limited spaces around the Holy Mosque has created a "severe filtration" as the residential areas are being expelled to the outside regions. Nowadays, hotels and commercial activities are the only features that can be seen in the neighborhood of the Holy Mosque. Residential activities are no longer in competition simply because the housing benefits are very less when compared with the commercial establishments of tourism. The abundance of transportation, land parcels and facilities have encourage the population used to live in downtown near the Holy Mosque to sell their properties to again extra benefit.

As a result of the recent development for the city structure, the arrival of pilgrims in Mecca until departure, make the city suffers from many urban problems. Additionally, the Mina area itself is considerably small and covers only $4.8 \mathrm{~km}^{2}$, thus insufficient to accommodate millions of pilgrims during Hajj. Recently, many of the pilgrims are being forced to find alternative accommodation, either in hotels or houses, or sleep on the ground and in the streets using tents. In the city of Mecca, the religious service, especially the pilgrimage, is the "lifeblood" driving force of economic activity and the main source of income of the largest number of Meccans. In fact, every growth in the number of pilgrims affects the urban expansion of the city. This issue will be the focus of this research.

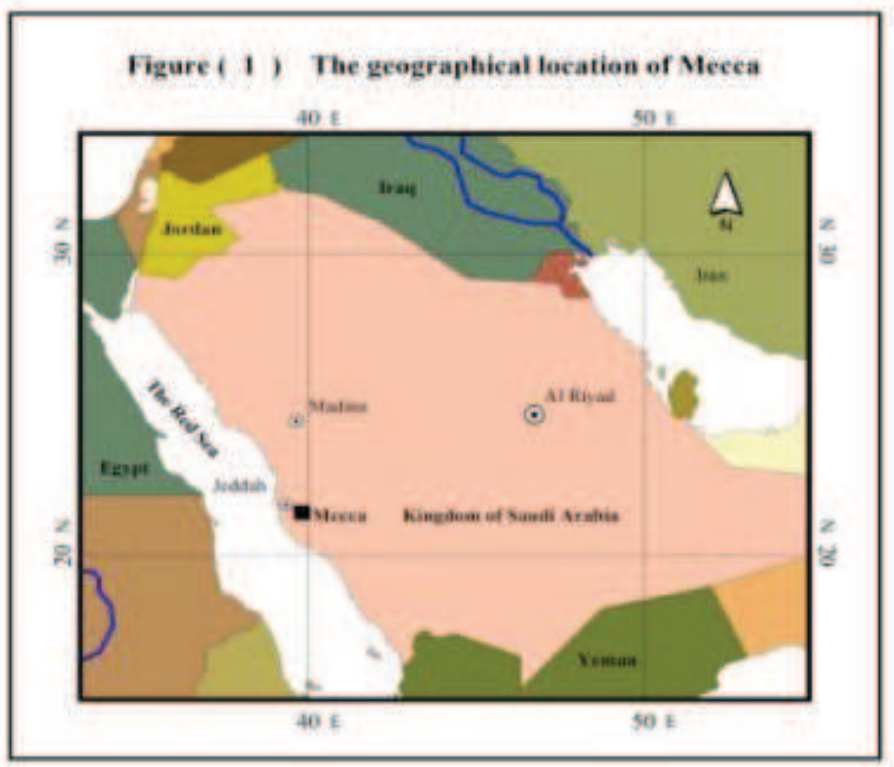

\section{Objectives and methodology}

This research aims to study the evolution of the number of pilgrims and the urban growth and its trend of the city of Mecca. This is to investigate the spatial development of the different neighborhoods since the year 1955

5 Office of General statistics and information, General Census of pilgrims in 2011 
and the development of pilgrim's numbers during the period from 1995 to recent as earlier records are not available. The drastic urban change in Mecca started to occur in 1955 where King AbudlAzizi added the first extension to the Holy Mosque in the Saudi era. The outcomes of these correlations could give projections to estimate the number of pilgrims and the city growth in the coming years. The value of this research may also contribute to the regional planning where these projections will identify the most suitable areas for the prospective extension of the city.

Several steps will be followed to perform the analyses of the number of pilgrims and urban growth as follows. 1), the number of pilgrims and its evolution will be collected and analyzed using graphical and statistical techniques. It will be investigated by analyzing the number changes (workforce), depending on the official government censuses that represent the main and fundamental of our study source.

2) Secondly, Satellite images and available topographic and cadastral maps will be collected and analyzed using geographic information system (GIS), in order to detect and map the spatial extent of urban areas at different periods. The research will also determine the urban problems that afflict the city aspiring in order to expose them to the city planners.

\section{The evolution of the number of pilgrims}

The number of pilgrims is calculated from the data collected by the Saudi check points, which are distributed on its borders (airports, ports, etc). However, the Ministry of Interior is responsible to allow (i.e. count) the pilgrims coming from outside the Kingdom of Saudi Arabia. The interior pilgrims from the different parts of the Kingdom or who live in the city of Mecca (i.e. interior pilgrims) are not being exactly counted. Additionally, considerable numbers of the interior pilgrims are fiddling the rules by not registering with the Ministry of Hajj and local councils and licensed companies responsible for the Hajj organization. Therefore, the counted numbers who obtain a license for Hajj can not represent the true number of interior pilgrims.

\section{Figure (2) The location of the Holy Mesque and The Holy sites}

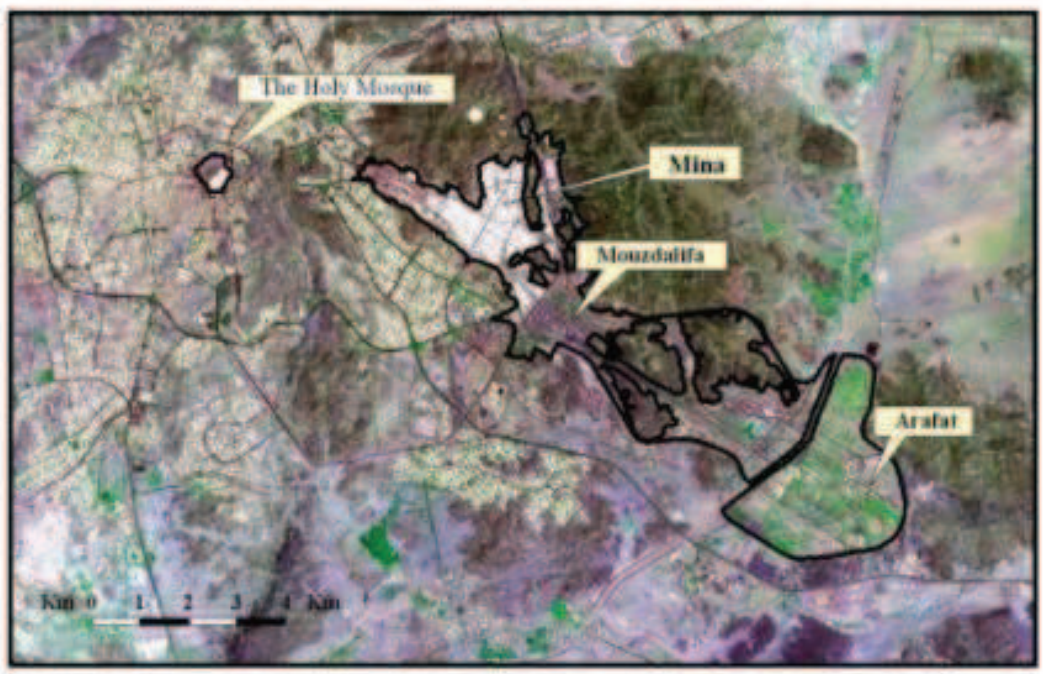

It is well known that hundreds of thousands or more than one million interior's pilgrims are performing pilgrimage without permission, and the Saudi authorities are trying to combat this phenomenon, but the huge gathering for Hajj takes place during very few days before Hajj and the check points cannot control it properly. In fact, interior pilgrims, who did not permitted pilgrimage, are the heaviest burden on residential capacity of the 
city and the capacity of public services, because pilgrimage permits provides a place for both pilgrims in Mina or Arafat or in a hotel or houses authorized for living of pilgrims in the city.

According to data provided by the Office of General statistics and information, the total number of pilgrims reached 2.9 million in 2011. In the light of the table (1) that corresponds to the number of pilgrims (interior and exterior) and their annual growth rate from 1995 to 2011, the number of pilgrims increased, interior pilgrims or exterior pilgrims. The annual growth rate reached 5\% in 2011.

The year 2010 witnessed the highest rate of pilgrim's annual growth and it reached $20,6 \%$. The reasons for this unprecedented rise in 2010 refer to the decrease in the number of pilgrims in the two previous years (2008 and 2009) where the pilgrims annual growth rate was negative and reached $-4 \%$ and $-1,9 \%$ respectively. This decrease is due to a fear of some countries of the epidemic of swine flu and avian influenza during those years, which led to emphasize the pilgrims travel to their destination country or time entered the territory of the Kingdom. During 2010 the interior pilgrims have contributed to such rise in the annual growth rates as it increased by $41,5 \%$ than the previous year. While the increase in the rate of exterior pilgrims was only $11,5 \%$ than 2009. In general, the numbers of pilgrims fluctuate from one year another, and the average annual rate is $3 \%$ through the investigation period. Given the annual increase of pilgrims; it is very important to analyze the urban changes in Mecca to investigate the relationship between pilgrims and urban. This relationship has its own significance as pilgrims numbers are anticipated to continue growing during the coming decades, so the response of urban to these changes have to be assessed.

Table 1: The measured and estimated growth rate of the pilgrims between 1995 and 2020

\begin{tabular}{|l|l|l|l|l|l|c|}
\hline Year & $\begin{array}{c}\text { Interior } \\
\text { pilgrims }\end{array}$ & $\begin{array}{c}\text { Rate of } \\
\text { annual } \\
\text { growth } \\
\%\end{array}$ & Exteriorpilgrims & $\begin{array}{c}\text { Rate of } \\
\text { annual } \\
\text { growth } \\
\%\end{array}$ & Total & $\begin{array}{c}\text { Rate of annual } \\
\text { growth } \\
\%\end{array}$ \\
\hline 1995 & 784769 & - & 1080465 & - & 1865234 & - \\
\hline 1996 & 774260 & -1.3 & 1168591 & 8.2 & 1942850 & 4.2 \\
\hline 1997 & 699770 & -9.6 & 1132344 & -3.1 & 1832104 & -5.7 \\
\hline 1998 & 775268 & 10.8 & 1056730 & -6.7 & 1832009 & 0.0 \\
\hline 1999 & 571599 & -26.3 & 1267555 & 20.0 & 1839128 & 0.4 \\
\hline 2000 & 549271 & -3.9 & 1363992 & 7.6 & 1913259 & 4.0 \\
\hline 2001 & 590576 & 7.5 & 1354184 & -0.7 & 1944768 & 1.6 \\
\hline 2002 & 610117 & 3.3 & 1431012 & 5.7 & 2041132 & 5.0 \\
\hline 2003 & 592368 & -2.9 & 1419706 & -0.8 & 2012071 & -1.4 \\
\hline 2004 & 629710 & 6.3 & 1534769 & 8.1 & 2164485 & 7.6 \\
\hline 2005 & 700603 & 11.3 & 1557447 & 1.5 & 2258061 & 4.3 \\
\hline 2006 & 724229 & 3.4 & 1654407 & 6.2 & 2378639 & 5.3 \\
\hline 2007 & 746511 & 3.1 & 1707814 & 3.2 & 2454328 & 3.2 \\
\hline 2008 & 679008 & -9.0 & 1729841 & 1.3 & 2408840 & -1.9 \\
\hline 2009 & 699313 & 3.0 & 1613965 & -6.7 & 2313281 & -4.0 \\
\hline 2010 & 989798 & 41.5 & 1799601 & 11.5 & 2789441 & 20.6 \\
\hline 2011 & 1099522 & 11.1 & 1828195 & 1.6 & 2927728 & 5.0 \\
\hline 2015 & 1272834 & 5.0 & 2116364 & 5.0 & 3389198 & 5.0 \\
\hline 2020 & 1624495 & 5.0 & 2701077 & 5.0 & 4325572 & 5.0 \\
\hline
\end{tabular}

Source: Office of General statistics and information, General Census of pilgrims in 2011and the estimates by the author 


\section{Analysis of the urban growth and its phases:}

The urban growth of Mecca was analyzed using GIS for the urban space as traced on various topographic maps, aerial photos and satellite images covering the period from 1955 to 2011 ( Fig).

The first documented urban extent of the town is shown on the produced topographic map of 1955 which has been used as a nuclei to specify the consequent phases of growth. Through the spatial analysis of GIS for the different layers we can distinguish three distinct phases in the spatial evolution and development of the city. The nuclei phase is characterized by the confined distribution only around The Holy Mosque. The topographic barriers such as mountains are the main limiting factor for the city lateral spreading. The first phase (from 1955 to 1986) has witnesses a rapid growth; the tunnels have been constructed in Mecca to connect the new neighborhoods with the old city nuclei. During this phase, the Holy Mosque has witnessed the first Saudi extension and modernization on the expense of surrounding anarchy areas. The second phase has started from 1986 to the present and is characterized by extensive modernization of old urban areas, the consumption of space parcels, and for the first time the development of urban areas on rock-cut parcels at the footslopes of surrounding mountains. The new plans for housing is now stretching on alluvial soil outside the old city core and being connected by modern networks and some 60 tunnels.

\subsection{The nuclei phase (before 1955)}

Examination of the table (2) shows that the area of the city has not exceeded 700 hectares until the year 1955. Mecca was essentially especially enlarged around the Holy Mosque and Mina (the nearest holy place of the Holy Mosque). The mountains controlled the urban pattern and forced the urban extension to be confined to the dry valleys in vicinity of the Holly Mosque (figure 3). It should be noted that at this phase, it was not planned spaces or schema town, the most part of neighborhoods have been completely taken the spontaneous type.

Table ( 2 ): The urban phases of the city of Mecca from 1955 to 2030

\begin{tabular}{|c|c|c|c|}
\hline Phase of urbangrowth & $\begin{array}{c}\text { area } \\
\text { in hectare }\end{array}$ & $\begin{array}{c}\text { Rate annual } \\
\text { moyen } \\
\%\end{array}$ & $\begin{array}{c}\text { Total growth } \\
\text { during the phase } \\
\%\end{array}$ \\
\hline Phase of slow growth (before 1955) & 711 & - & - \\
\hline Phase of rapid growth (1955-1986) & 4721.4 & 11.33 & 528.4 \\
\hline Stage of moderate growth (1986-2011) & 24946.1 & 8.12 & 164.6 \\
\hline Estimates for 2020 & 41051.4 & 8.07 & 180.7 \\
\hline Estimate for 2030 & 74179.8 & 8.07 & \\
\hline
\end{tabular}

Source: Al-Ghamdi, Al-Najjar 2000, The Master Plan of the city of Mecca until the year 2030, the estimates calculated by the researcher

\subsection{Phase of rapid growth (1955-1986)}

This phase of urbanization in the era of the Saudi State is the most important phase in the history of the city where the mechanism for reconstruction and urban expansion is seen. The revenue of the oil provides the capital that helped dig the tunnels, to partially eliminate parts of the mountains in the surrounding of the Holly Mosque, so the urbanization has benefited from the economic growth and the huge and modern road networks were being constructed. This network connects, a hand, parts of the city one by one, and on the other hand, it connects the city to different cities and regions all the Kingdom, especially the most important cities of Jeddah ${ }^{6}$ and Medina.

6 The city of Jeddah contains the nearst access port via King Abdulaziz international airport which includes a special terminal for the pilgrimage. 
At this phase, strategic plans have been developed for the planning of the city of Mecca on a scientific basis. In 1955, projects are launched to expand the area of the Holy Mosque by King Abdul Aziz. These projects required the moving of the houses located around the Holy Mosque, and sometimes even whole neighborhoods move, this has led to the continued migration of residential built from the center to the margins of the city and to create new housing plans. In the development of strategic plans for the future planning of the city, it has also taken into account to establish a modern network infrastructure and a network of public services and attention to the development and expansion of the area of the Holy places of pilgrimage (Mina, Muzdalifah and Arafat).

The demolition and removal of hundreds of homes near the Holy Mosque due to expansion projects, have led to the phenomenon of population movements from downtown to the outside. Several writers and authors, who have studied the urbanization, spoke of this phenomenon and its impact on the growth of the urban peripheries $^{7}$. The move of the population of the city centre to peripheries areas is an essential element of the mechanism of the extension of Mecca which peripheral growth never ceased during the period of our study. The continuous accumulation of the population in the city has led to a projection outward especially in the dry valleys near, and so it appeared new residential and spontaneous neighborhoods, which had been on the slums occupied by huts, as the renaissance of the neighborhoods of Jarwal, Al-Hendawyah and Tundpauy (M.Syriani, 1986). The expansion of the city began to expand westward, favored by the flat land suitable for building.

By the end of this growth phase, the total built-up spaces of the city; were nearly increased by six times during 31 years (664\%). The pre-rapid growth phase has only covered 711 hectares of build up area, then the city has gained additional 4010.4 hectares, thus making the total build up areas to 4721 hectares in 1986. However, the mean annual growth rate of this growth period is estimated to $18,2 \%$, but intra-changes have been recorded. Between 1978 and 1986, the city has seen greater urban extension that has marked the history of the Mecca. For nearly eight years, the urban area of the town increased from 2343 to 4721 hectares with an average annual growth rate of $12,7 \%$.

The urban changes have also affected the central neighborhoods of the Holy Mosque and the urban tissue of the pre-1955 was deeply altered. The old urbannuclei are largely transformed, leaving the place, proximity to the center, to large complexes commercial establishments and giants hotels. All empty spaces in the central neighborhoods are no longer available.

Figure (3) The urban phases of the city of Mecca from 1955 to 2030

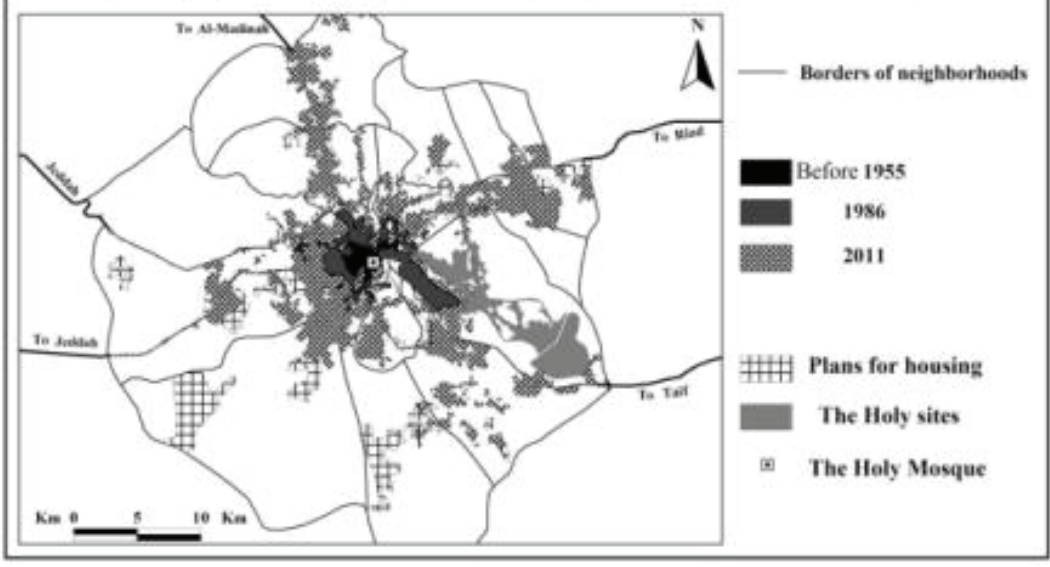

\subsection{Stage of moderate growth (1986-2011)}

As shown in table (2) and figure (3), the city increased by 20224.7 hectares during these 25 years. The urban extension of the metropolitan area has filled in large part all the space between the neighborhoods and sections 
of the city, such as AIAzizya. The city has also stretched along the roads laid down along the wadis, mostly in the northeast direction (i.e. to Madina). The tributaries of this main wadi has also been built and connected to the urban mass of the city. The extension of Mecca is almost proceeding in all directions, particularly in the Southeast, where the plains of Wadi-Orna are very immense and considered strategic to Arafat and Muzdalipha. The rate of annual growth has slowed considerably where urban extension is mainly dominated by saturation and densification of spaces developed in parallel with the new extensions, including the central areas of the city. Again, the peripheral extension is made all around the Mecca in fringes, depending on the route of the dry valleys or roads.

In 2011, the city is composed from the mass built with proportionally high annual growth rates, when the average annual growth rate in thirty-five years previous was $8 \%$ per year. The mountains are valued more than before, where they become a stock or real estate reserve, especially in areas near the Holy Mosque and the holy sites. One can notice in the neighborhoods of Alazizya, Elshysha and Almabidh, the phenomenon of the demolition of the slopes of the mountain (Piedmont) and the construction of residential towers devoted to exploitation, which has changed the natural morphology of the city.

It took also demolishing large parts of mountains around the Holy Mosque to enlarge and extend it, and at the same time gives up space needed for the construction of the infrastructure of the Holy Mosque (prayer open spaces, bus stations, streets and tunnels dedicated to pilgrims). Although the demolition of large parts of the mountains gave planners enough necessary space to perform their projects, it resulted in a negative impact affecting the fragmented rocks that sometimes cause a hazard on the urban cover and road networks in the long term.

The creation of new ring-roads and the completion of many tunnels have sometimes great impact on the increase in urban mass, where all areas have become accessible. Urban expansion is extended to all directions, including to the North, where it extended for a distance of $20 \mathrm{~km}$, in the neighborhoods of Al-taneem and towards the town of Aljmom, and South-West off the old road to Jeddah. The extension also reached $12 \mathrm{~km}$ to the South to include the neighborhood of Al-azizya. For this reason and the limited spaces in these strategic neighborhoods, the government has created a buffer zone between the Holy places and the new urban branches.

As a result, residential neighborhoods are only allowed to the South of the Al Mashaeer (the Holy sites).

Given the scale of the housing needs - especially after the extension of the hotels and the commercials centers in downtown, and the migration of the residential activity to the fringes of the city, the government has allowed the establishment of different plans around the city. This situation helped to extend the city horizontally and also created independent nucleus of the existing urban fabric around the city. Indeed, these new nuclei can sever as independent suburbs. For example, this plan of Sharayaa east of the city has been evolved from a small private plan to a whole neighborhood (Al-Seryani, 1986).

\section{The main results}

It cannot be ignored that the gathering of millions of people at the same time in the same space, for a few days, contributes to a lot of problems relating to the environment and the urban organization. The mean annual growth rate of pilgrims is estimated to $5 \%$ and keeping the same trend will make the pilgrim numbers to reach 4.3 millions by 2020. Additionally, 1.7 million local pilgrims are expected to gather in Mecca during the same period. Currently, during the Hajj all neighborhoods and streets of the Holy places suffer from several problems that are at the origin of this event. Therefore, the congestion will continue to increase and mitigation measures are definitely required to successfully manage the crowds. Indeed the city of Mecca will continue to grow due to population growth as well as because of Hajj. Given the estimated numbers and areas in this research, it is predicted that the urban of the city will reach 41051 hectares in 2020. Furthermore, if the annual growth rate remains at $8,1 \%$, the urban area will reach 74179.8 hectares in 2030 . The obtained figures are alarming to the future needs of Mecca, in order to meet the required urban spaces and population facilities. Therefore, a special attention should be paid to the environmental aspects of the available land areas for urban extension to assess the potential hazards including flash floods, groundwater contamination and environmental degradation, etc. The implications of Hajj have been identified as follows: 
Social issues:

The habitat is the first victim of the pilgrimage season. The accelerated increase of pilgrims in a limited space resulted in a real housing crisis. The rental price has incredibly increased at the time where the private construction of new housing projects has disappeared. All new buildings in the city center are designed for hotels or commercials activities. Moreover, many habitats for existing private dwellings are in an improper state and on track to be substituted by giant's hotels.

We can say, without exaggeration, that the housing crisis has affected all the neighborhoods near of holy places. We find a unique phenomenon (eviction and deportation during the pilgrimage season), that is, the resident must leave the home or apartment during the days of Hajj (if tenant). In this case, the owners rent their buildings to the pilgrims at very high prices, causing many problems for residents who cannot find another individual or family accommodation. There are many houses and hotels that are closed throughout the year and operated only during the pilgrimage season. As a result, there is a loss of housing wealth has not exploited the optimal economic exploitation. On the other hand, it follows a lack of housing available for in these neighborhoods.

\section{Health issues:}

Although DUMORTIER Brigitte said "today the ministry of pilgrimage and endowments oversees the Hajj and pilgrims whose number has increased from a few thousand each year to two million, no longer have to fear that discomfort, sometimes fatal, due to the fatigue of travel, heat, fasting, emotion"(DUMORTIER B., 1997, p.155). We can prove that there is a danger that threatens the health of the pilgrims. Dispersal of the pilgrims on the different hotels and private accommodation, adding poor pilgrims who can not live in hotels and sleep in the streets of the near neighborhoods of the rites, lead to difficulties in controlling the spread of an epidemic. The city also suffers from the overload on health establishments, which leads to shortages in the service of the populations in these neighborhoods.

The pollution during the days of the pilgrimage is also a serious problem. J.BASTIE and B.DÉZERT (1991, p. 318) confirmed that "the formation of "layers of grime" over large agglomerations are caused by modern urban concentration and the development of the car". Therefore, the means of transport have a major role in air pollution especially with large numbers during the pilgrimage season. They release gas and, therefore, odors. P. MERLIN (1991, p. 269) believes in "50\% share of traffic pollution in the air ".

"The gaseous releases of various types of vehicles (motorcycles, cars, buses and trucks) are of petroleum origin: in decreasing order, oxides of carbon (cause difficulty breathing especially to starts, accelerations and decelerations during incomplete combustion), hydrocarbons, which some irritate the eyes and mucous membranes, the oxides of nitrogen in congested places acting on the lungs, heavy metals especially lead" (E.MERENNE (1995, p. 172). Another type of pollution comes from the wastes that accumulate in open areas, sometimes on a side street in the near neighborhoods of the shrines, especially Al-Azizya. Much of unpleasant odors occur at these locations.

\section{Public services and the security issues:}

The dissemination of pilgrims in the neighborhoods precludes the provision of the necessary services. Their consumption exceeds the capacity of existing public services in the city, primarily the drainage service and the supply of drinking water. The streets of spontaneous areas are mostly narrow and this fact impact heavily on the daily life of the population. Sometimes the extension of infrastructure site closes these streets.

Traffic is a real problem in the city of the Mecca. The failure in public transport where most population has private car, results in suffering of the population in their movements in the city. People lose a lot of time to return the work at home. At peak hours, all the streets of the city suffer from congestion. Thousands of students and officials use private transport. Traffic congestion causes the spread of the phenomenon of bottling, which leads to the difficulty of movement of ambulances, civil defense and police in case of disasters such as fires or accidents. 


\section{Conclusion}

Mecca has given credibility undeniable regional metropolis due to its unique urban, Hajj and population patterns. Regarding the gradual increase in the rate of pilgrims accompanied by changes in the land use and a high rate of the built mass, are a true indicator of urban development of Mecca. The pilgrimage season has provided stable income of the population; this fact has led to the growth in tourism and the commercial sector. Road networks oriented forms of the spatial growth of the agglomeration on linear modes. The vertical extension is also an important form of urban growth. In recent decades, this type of extension has been a new trend in planning in response to the demand for the accommodation of pilgrims.

The movement of population from the city centre to the outside represented a type of mechanism including the growth of the urban peripheries. The peripheral growth of Mecca has never ceased during the period of our study, the phase of rapid growth witnessed $11 \%$ increase in the urban areas and the estimated annual increase will continue at $8 \%$. Indeed, the value of locations are driving factors that determine movement to the movements outside from the city centre, and it may led to a conflict between different activities within the city districts. The high price of the land parcels and the competition from tertiary activities on housing in the city centre led to a migration companies and institutions to urban peripheries, which represents another form of the mechanisms of the growth of Mecca. The increase continues in the number of pilgrims and the rapid urban growth has posed problems, health, social, utilities, security and the environment.

\section{References}

Ascoura Ibrahim, Some aspects of urban growth's dynamics for the Holy City of Makkah, Geography and Contemporary Global Changes Conference, Almadinah Almunawwarah, 1-4 april 2013

D Umortier Brigitte, 1997, Géographie de l'Orient Arabe, Armand Colin, Paris, 212 p.

Bastie Jean, Dezert Bernard, 1991, La ville, Masson, Paris, 416 p.

Office of General statistics and information, General Census of pilgrims in 2011

Central Department of Statistics and Information, population censuses and census of establishments

"The general condition of the buildings which remain pilgrims to Mecca during the pilgrimage," Bulletin of the Geographical Society Kuwait, number, vol. 65, pp. 40

Le Royaume de l'Arabie Saoudite, 1979, Stacey International, London, p.256

The Master Plan of the city of Mecca until the year 2030

Merenne Émile, 1995, Géographie des transports, Nathan, Paris, 192 p.

Merlin Pierre, 1991, Géographie, économie et planification des transports, PUF, Paris, 472 P.

Mohamed Mahmoud Al-Seryani, 1986, "Mecca, a study in urban growth", Bulletin of the society of geography Kuwait, number, vol. 87, pp. 77

Noin Daniel, 1998, "Géographie de la population", 5e édition, Armand Colin, Paris, 278 p.

Saad Al-Ghamdi, Mohammad Al-Najjar, 2002, ' analysis of urban growth and its trends through the use of remote sensing data: a study on the city of Mecca from 1978 to 2000 ", Journal of King Abdulaziz University, a special issue, pp 231-273 
